\title{
Crystal Beam Technology with Special Resolution
}

\author{
Vardanyan $\mathrm{J}^{1 *}$, Hovhannisyan $\mathbf{M}^{1}$, Mkhitaryan $\mathrm{C}^{1}$, Nersisyan $\mathbf{M}^{2}$ and \\ Agajanyan $\mathrm{H}^{1}$ \\ ${ }^{1}$ Institute of Applied Problems of Physics, RA National Academy of Sciences, Armenia \\ ${ }^{2}$ Institute of Physical Research, RA National Academy of Sciences, Armenia
}

\section{Research Article \\ Volume 3 Issue 4}

Received Date: November 07, 2019

Published Date: November 15, 2019

*Corresponding author: Vardanyan Julia, Institute of Applied Problems of Physics, RA National Academy of Sciences, Erevan, Armenia, Tel: (+374)93975257; Email: julia.vardanyan2011@yandex.ru

\section{Abstract}

A crystal beam technology was developed in order to create a detector with a spatial resolution in which the resolution is determined by the size of the element of corundum crystals assembled into a mosaic. By mechanical methods, crystalline fibers with a size of $0.25 \times 0.25 \times 2.5 \mathrm{~mm}$ were obtained. "Bundle" - a matrix of converters was made, and images were obtained using a web camera. The sequence of operations is similar to technology FOR (fiber optic plate) or MCR (multichannel plate).

Keywords: Crystal beam technology; Spatial resolution; Corundum crystals; Spatial resolution; Crystalline fibers

\section{Introduction}

Under the registration of spectra understand the definition of the dependence of the radiation energy on the wavelength using the registration system. The registration system usually includes a photoelectric radiation receiver that converts the energy of light radiation into an electrical signal, hardware and software for processing and visualization of this signal. Depending on the type of radiation detector used, the following types of registration systems are distinguished: integral and with imaging.

Integrated registration systems include systems in which detectors are used as radiation detectors, which convert the entire radiation flux (integral light flux) into an electrical signal, without determining the distribution of radiation energy over wavelengths. This type of detector includes photomultiplier tubes (PMTs), photodiodes, and other types of similar detectors.

Image-building systems include systems in which linear or matrix multi-element photo detectors are used as radiation detectors. Such registration systems are used in cases where, in addition to measuring the amount of energy of optical radiation, a determination is made of the distribution of radiation energy over wavelengths.

There are linear and matrix detectors based on silicon structures [1,2], which have a spectral sensitivity range from 200 to $1100 \mathrm{~nm}$ (ultraviolet, visible, and near infrared spectral regions). These are the most widely used linear detectors due to their relative cheapness. Linear detectors for the near infrared region of the spectrum the spectral sensitivity range from 900 to $\sim 2500 \mathrm{~nm}$ - are quite expensive.

Linear detectors for other spectral ranges are either very expensive or not manufactured at all. Thus, one of the limitations of using linear detectors is their rather narrow range of spectral sensitivity. Therefore, the need to expand the range of spectral sensitivity of the detectors is an urgent task. 


\section{Physical Science \& Biophysics Journal}

\section{Experimental Part}

The work to create a spatial resolution detector based on corundum, in which the resolution is determined by the size of the corundum crystal element assembled into a mosaic, is carried out in several stages.

The first stage is the selection of crystal samples for research. For this, first of all, it was necessary to certify crystal samples. To assess the optical quality of crystals and for optical studies, it is sufficient to make samples according to two criteria-bubbles, impurities, and their concentration. For design work, it was quite enough to measure the presence of bubbles, their size and concentration. Similar measurements are made with a conventional microscope, and webcams and digital cameras are used to fix (capture images).

The second essential criterion for certification of crystals is the determination of the presence and concentration of dopants used in crystals. The availability and controlled insertion of dopants and the change in structural perfection (annealing of crystals) are decisive driving and changing parameters that determine the luminescent qualities of crystals $[3,4,5]$.

The determination of dopants and their concentration were measured on an Armtek X-ray fluorescence spectrometer Table 1.

\begin{tabular}{|c|c|c|c|c|c|c|c|c|c|}
\hline \multirow[b]{2}{*}{ Element } & \multirow[b]{2}{*}{ No1 } & \multirow[b]{2}{*}{ No4 } & \multirow[b]{2}{*}{ No5 } & \multirow[b]{2}{*}{ No7 } & \multicolumn{5}{|c|}{ Sample } \\
\hline & & & & & No8 & \begin{tabular}{|c|}
$\begin{array}{c}\text { Corundum } \\
\text { (25kev) }\end{array}$ \\
\end{tabular} & $\begin{array}{c}\text { Ruby } \\
\text { Natural }\end{array}$ & \begin{tabular}{|c|}
$\begin{array}{c}\text { Ruby Natural } \\
\text { (With K) }\end{array}$ \\
\end{tabular} & $\begin{array}{c}\text { Corundum } \\
\text { White }\end{array}$ \\
\hline "Al" & 99.6146 & 99.4299 & 98.8347 & 98.6095 & 98.8347 & 99.7539 & 96.2494 & 94.46476 & 99.7417 \\
\hline "Sc" & - & 1.09E-02 & - & - & - & - & - & - & - \\
\hline "Ti" & 9.03E-03 & - & - & $1.60 \mathrm{E}-02$ & - & - & 0.35254 & 0.44435 & 7.19E-04 \\
\hline "V" & $1.57 \mathrm{E}-03$ & 0.06795 & 0.31668 & $8.92 \mathrm{E}-02$ & 0.31668 & - & 0.17215 & 0.26881 & - \\
\hline "Cr" & 8.05E-02 & 0.25776 & 0.46574 & 0.48724 & 0.46574 & $3.64 \mathrm{E}-02$ & 1.34435 & 1.83645 & $3.37 \mathrm{E}-02$ \\
\hline "Fe" & 3.38E-02 & 6.43E-02 & $7.66 \mathrm{E}-02$ & 3.55E-02 & $7.66 \mathrm{E}-02$ & $1.58 \mathrm{E}-02$ & 1.52497 & 2.35893 & $1.83 \mathrm{E}-02$ \\
\hline "Co" & 2.69E-02 & $1.65 \mathrm{E}-02$ & 0.10648 & 0.15392 & 0.10648 & - & - & - & $2.52 \mathrm{E}-02$ \\
\hline "Ni" & - & - & - & $8.89 \mathrm{E}-03$ & - & $7.05 \mathrm{E}-03$ & 0.13923 & 0.23894 & - \\
\hline "Cu" & - & - & - & - & - & - & 8.24E-02 & 0.14544 & 0.05507 \\
\hline "Zn" & 0.01469 & $1.42 \mathrm{E}-02$ & 3.86E-02 & $1.58 \mathrm{E}-02$ & $3.86 \mathrm{E}-02$ & 0.10112 & 4.92E-02 & $8.50 \mathrm{E}-02$ & - \\
\hline "Ga" & 1.49E-02 & - & 9.24E-02 & 7.11E-02 & $9.24 \mathrm{E}-02$ & - & 0.04036 & 7.57E-02 & - \\
\hline "As" & 0.15426 & 0.11706 & - & 0.51287 & - & $5.09 \mathrm{E}-02$ & - & - & 0.01223 \\
\hline "Sr" & - & - & - & - & - & $9.61 \mathrm{E}-03$ & - & - & - \\
\hline "Se" & 4.97E-02 & $2.13 \mathrm{E}-02$ & 6.89E-02 & - & $6.89 \mathrm{E}-02$ & - & $4.54 \mathrm{E}-02$ & 8.15E-02 & - \\
\hline "Mo" & - & - & - & - & - & $1.75 \mathrm{E}-02$ & - & - & - \\
\hline
\end{tabular}

Table 1: Dopant samples composition and concentration: measurements by AMPTEK equipment [6].

To create a detector with spatial resolution, a crystal beam technology was developed, and corundum (which has excellent optical data) with different impurities was used as a crystal. We chose those crystal samples that had wide absorption bands in the VUV, UV, and IR spectral regions. The sequence of operations is similar to the technology FOR (fiber optic plate) or MCR (multi-channel plate) [7].

The sequence of operations is described in Figure 2. Samples were obtained from boulder single crystals of corundum by optical-mechanical processing. An ultrasonic unit was used to cut matrix crystalline elements. Received crystals with a thickness of $250 \mu \mathrm{m}$ and a width of $250 \mu \mathrm{m}$ (Figure 1).

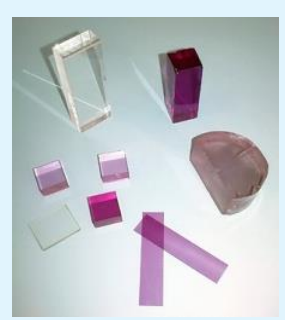

Figure 1: Crystals with a thickness of $250 \mu \mathrm{m}$ and a width of $250 \mu \mathrm{m}$. 


\section{Physical Science \& Biophysics Journal}

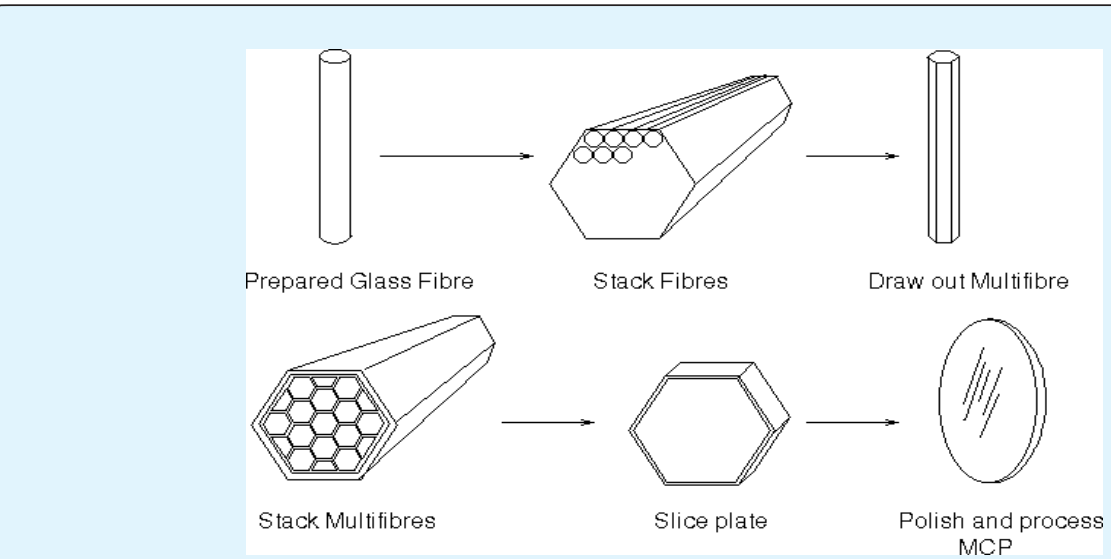

Figure 2: The order and sequence of the operations for creation of fiber optic plates.

After a separate fiber element has been prepared, it should be polished (both mechanically and chemically polished), coated with a connecting material (nickel, copper, silver, platinum, etc.). "Knitted"- together, cut into plates and therefore "bundle" must undergo final processing. To improve the technology, first the processing of simple glass fibers (diameter $0.5-0.25 \mathrm{~mm}$ ) with nickel, copper, argentine low-temperature dispersion powder at a temperature of $2500^{\circ} \mathrm{C}$ was applied. Then quartz samples with a diameter of 0.5-1.0 $\mathrm{mm}$ were made, and the technology on them was improved, and then they switched to the manufacture of corundum plates.

A "bundle"-matrix of converters was made (Figure 3-7).
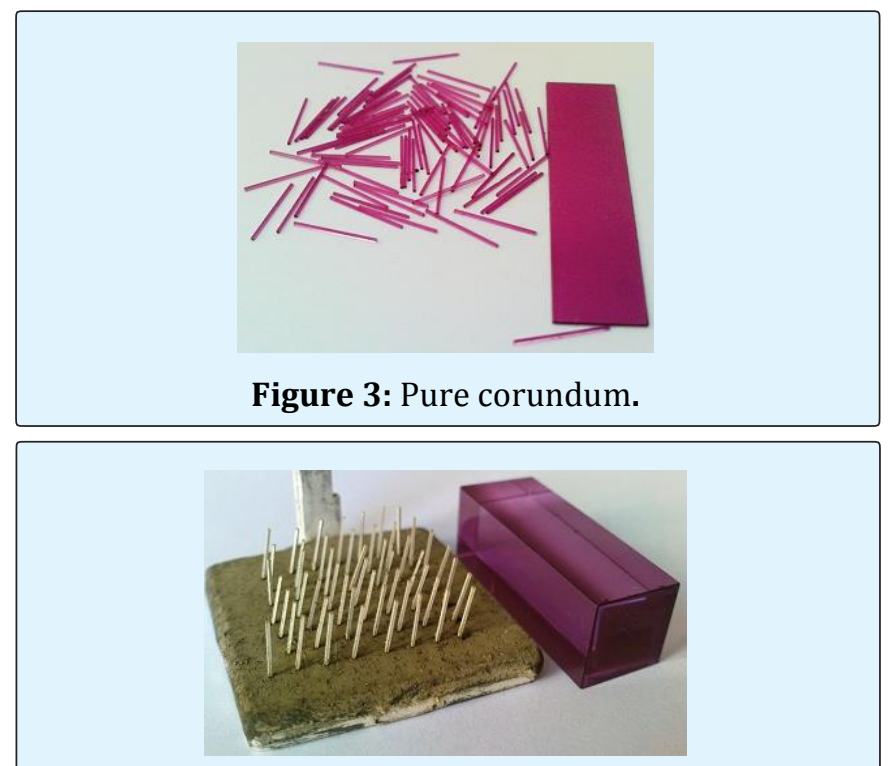

Figure 4: Corundum covered by silver.

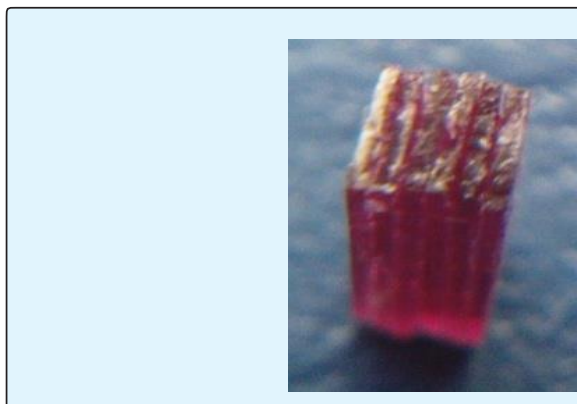

Figure 5: Pure corundum- $0.25 \mathrm{x} 0.25 \mathrm{x} 8.0 \mathrm{~mm}$.

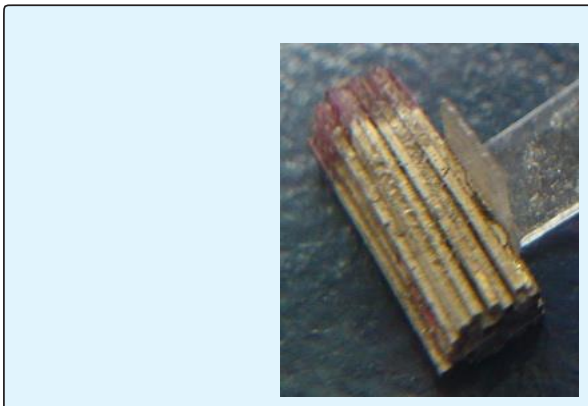

Figure 6: Covered by silver $0.25 \times 0.25 \times 8.0 \mathrm{~mm}$.

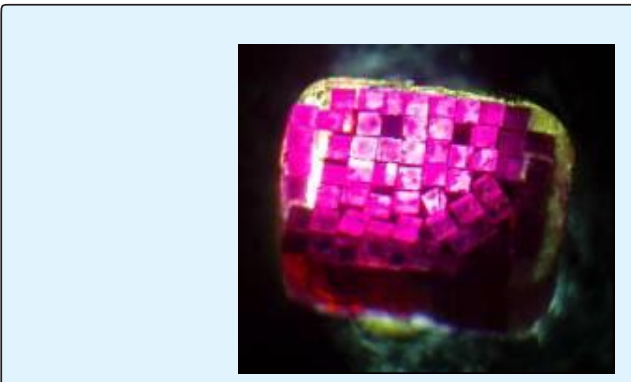

Figure 7: Pure corundum- $0.25 \times 0.25 \times 2.5 \mathrm{~mm}$. 


\section{Physical Science \& Biophysics Journal}

\section{Results}

Single-crystal corundum samples with various dopants, their optical properties, absorption spectra, and luminescence spectra were studied. Crystals were selected for the manufacture of fibers with a size of $0.25 \times 0.25 \times 2.5 \mathrm{~mm}$. A "bundle" of pre-converters matrix was made, the matrix was combined and images were obtained using webcams.

\section{Conclusion}

To improve the spatial resolution of the detection system, it is necessary:

1. Improve the crystal beam technology

2. Get fiber crystals with a smaller diameter

3. Improve the optical performance of corundum crystals implanted in each fiber "bundle" impurities that have resonance absorption lines in the HUV, UV and IR radiation regions.

\section{References}

1. Rohr P (2003) Amorphous Silicon based matrix detectors for X-ray Imaging. ESRF Users Meeting, Grenoble, France.
2. Wang A (2011) Optical Fiber Sensors and Systems. Center for Photonics Technology, Virginia Polytechnic Institute and State University Blacksburg, USA.

3. Vardanyan J, Hovhannisyan $\mathrm{M}$, Agajanyan $\mathrm{H}$, Nersisyan M (2019) Evolution Corundum Based Detector in UV and HUV Spectral Region. Phy Sci \& Biophy J 3(3): 1-8.

4. Vardanyan J, Agajanyan H, Nersisyan M (2018) Receivers of VUV and UV Radiation. Armenian Journal of Physics 11(3): 141-144.

5. Vardanyan J, Agajanyan H, Nersisyan M (2019) Corundum Detector Converter. Armenian Journal of Physics 12(2): 213-217.

6. Aslyan Z, Madatyan K, Vardanyan J, Tsakanov V, Mikaelyan R (2006) Ruby based detector in UV and VUV spectral region. Brilliant Light in life and Material Sciences pp: 491-494.

7. Lopez-Higuera JM (2002) Handbook of Optical Fibre Sensing Technology. John Wiley \& Sons Inc, pp: 828. 